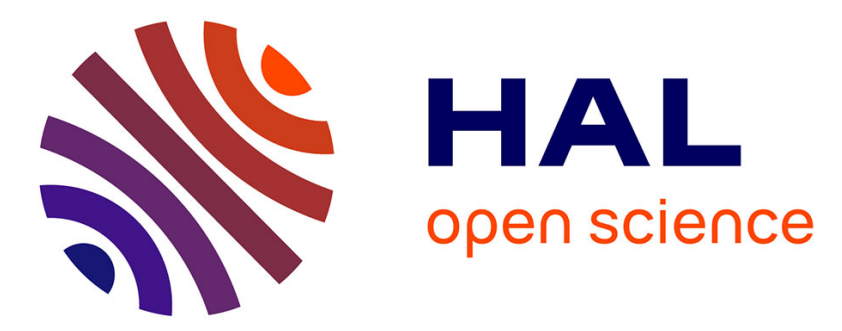

\title{
High-radiance light sources with LED-pumped luminescent concentrators applied to pump Nd:YAG passively Q-switched laser
}

P. Pichon, A Barbet, D. Blengino, P. Legavre, T Gallinelli, Frédéric Druon, J-P Blanchot, F Balembois, S Forget, S Chénais, et al.

\section{To cite this version:}

P. Pichon, A Barbet, D. Blengino, P. Legavre, T Gallinelli, et al.. High-radiance light sources with LED-pumped luminescent concentrators applied to pump Nd:YAG passively Q-switched laser. Optics and Laser Technology, 2017, 96, pp.7 - 12. 10.1016/j.optlastec.2017.04.009 . hal-02190903

\section{HAL Id: hal-02190903 https://hal.science/hal-02190903}

Submitted on 23 Jul 2019

HAL is a multi-disciplinary open access archive for the deposit and dissemination of scientific research documents, whether they are published or not. The documents may come from teaching and research institutions in France or abroad, or from public or private research centers.
L'archive ouverte pluridisciplinaire HAL, est destinée au dépôt et à la diffusion de documents scientifiques de niveau recherche, publiés ou non, émanant des établissements d'enseignement et de recherche français ou étrangers, des laboratoires publics ou privés. 


\title{
High-radiance light sources with LED-pumped luminescent concentrators applied to pump Nd:YAG passively Q-switched laser.
}

\author{
P. Pichon,,$^{1,2}$ A. Barbet,${ }^{1}$ D. Blengino, ${ }^{2}$ P. Legavre,${ }^{2}$ T. Gallinelli, ${ }^{3}$ F. Druon,${ }^{1, *}$ \\ J-P. Blanchot, ${ }^{2}$ F. Balembois, ${ }^{1}$ S. Forget ${ }^{3}$ S. Chénais ${ }^{3}$ and P. Georges ${ }^{1}$ \\ ${ }^{1}$ Laboratoire Charles Fabry, Institut d'Optique Graduate School, CNRS, Université Paris-Saclay, \\ 91127 Palaiseau Cedex, France \\ ${ }^{2}$ Effilux, 7 Avenue de l'Atlantique, 91940 Les Ulis, France \\ ${ }^{3}$ Laboratoire de Physique des Lasers, UMR 7538, Sorbonne Paris Cité, CNRS, Université Paris 13, F-93430, \\ Villetaneuse, France \\ *frederic.druon@institutoptique.fr
}

By power scaling of LEDs pump concentrators we demonstrated a visible light source (centered at $550 \mathrm{~nm}$ ) producing $294 \mathrm{~W}$ with a radiance of $668 \mathrm{~W} / \mathrm{cm}^{2} / \mathrm{sr}$ in the air. Using more than 1100 LEDs, this setup represents one order of magnitude improvement in terms of output power and brightest of LED pump concentrator ever reported.

We pushed further the concept of low cost high brightness light source using this concentrator to pump a very simple Nd:YAG laser in free running mode and in passively Q-switched regime using a Cr:YAG saturable absorber. Output energies up to $263 \mu \mathrm{J}$ with a pulse duration of $33 \mathrm{~ns}$ have been obtained at $1064 \mathrm{~nm}$, leading to a peak power of $8 \mathrm{~kW}$ in a TEM $\mathrm{TE}_{00}$ mode.

KEYWORDS: Lasers, neodymium, Lasers, Q-switched, Luminescent Concentrators, Light-emitting diodes.

\section{INTRODUCTION}

In the past decades, Light-Emitting Diodes (LEDs) technology has known a dramatic improvement in term of performance with, in parallel, an impressive decrease of their costs. Following the Haitz law [1], LED power increased by a factor 20 whereas its price was divided by 10 over ten years. However, LED radiance is still limited to the $50-100 \mathrm{~W} / \mathrm{cm}^{2} / \mathrm{sr}$ range, far below laser sources, limiting the field of applications. Sources with the cost of LED and the irradiance of lasers is consequently an horizon for research on solid state sources. Two solutions can be considered to develop ultra low cost high radiance sources. The first one is LED pumped lasers. Previously reported the mid 60's. [2], LED pumping vanished rapidly in the 1970's with the development of laser diodes. Recently, LED-pumping experienced a rebirth of interest driven by the solid-state lighting market. Various gain media and $\mathrm{Nd}^{3+}$ doped media in particular are now directly pumped by LEDs [3-5].

The second solution is related to luminescent concentrators (LCs). They are well known in the field of photovoltaic panels for sun light harvesting [6] and particle detection [7]. Using LEDs as primary source LCs have been thought as wavelength shifters or LEDs radiances enhancer [8,9]. Breaking the brightness conservation rule, LED-pumped concentrators can concentrate light toward its smallest facets. Ce:YAG LED-pumped concentrators with a radiance of $110 \mathrm{~W} / \mathrm{cm}^{2} / \mathrm{sr}$ and a $\mathrm{cW}$ output power of $17 \mathrm{~W}$ have been reported [8] and recently, by operating the LED in pulsed regime, a radiance of 150 $\mathrm{W} / \mathrm{cm}^{2} / \mathrm{sr}$ with a peak output power of $43 \mathrm{~W}$ has been recently demonstrated [9]. It corresponds to an enhancement of 4.5 and 2.5 respectively compared to the radiance of the LEDs used as pumped sources. This concept clearly provides a new type of bright broadband visible light source. 
However, LCs are sources of spontaneous emission intrinsically limiting the irradiance. It is thus interesting to consider how the light coming from two dimensions LED concentrators can be transformed by one dimension laser cavity. Indeed, LED concentrator pumping has already been demonstrated with $\mathrm{Nd}: \mathrm{YVO}_{4}$ [9], radiance in the order of $\mathrm{MW} / \mathrm{cm}^{2} / \mathrm{sr}$ can be obtained.

To go further on the route of ultra low-cost high radiance sources, one can consider temporal concentration of light by Qswitching of a laser cavity with a gain medium having a long lifetime. To achieve the lowest cost possible, the best way is passive Q-switching. An early attempt of direct LED-pumped Q-switched Nd:YAG laser was performed in 1984 by Kuratev et al. [10] at cryogenic temperature, but performance was limited with a laser average power in the $50 \mu \mathrm{W}$ range. With LED concentrators, the pump radiance is now large enough to revisit this concept at room temperature. As the output surface of LED concentrators is small, a laser setup with small gain media (10 mm range) and short cavity is possible. In addition, with large surfaces filled by LEDs, LED-pumped concentrators have a stronger potential of power scaling than direct LEDpumped laser where the number of LEDs is limited by the surface of the gain medium.

Based on these observations, this paper presents high radiance light sources power scaled Ce:YAG LED concentrators. Firstly, the design of a new LED-pumping architecture with state-of-the-art performance is presented. This setup represents one order of magnitude improvement in terms of energy compared to LED-pumped concentrators previously reported [9]. Secondly, we demonstrate that combining LED-pumping and luminescent concentrators can be used to pump an Nd:YAG laser. Thirdly, we demonstrated, to our best knowledge, the first passively Q-switched Nd:YAG laser using LED-pumping via a luminescent concentrator at room temperature and consists in a breakthrough for LED pumping systems.

\section{POWER SCALING OF THE LUMINESCENT CONCENTRATORS}

A luminescent concentrator is a slab with a large pumped surface [9]. The pump light is absorbed by luminophores $\left(\mathrm{Ce}^{3+}\right.$ ions in our case) and the reemitted light is guided through total internal reflections (TIR) to the edges of the LC (see Figure 1). The output power can be expressed by :

$$
P_{\text {out }}=\eta_{o / o} \cdot P_{L E D} \cdot \eta_{\text {fill }} \cdot S_{\text {pumped }} / S_{L E D}
$$

where $\eta_{o / o}$ is the optical efficiency of the LC, $P_{L E D}$ and $S_{L E D}$ are the output power and the emitting surface of one LED respectively, $\eta_{\text {fill }}$ is the LED density filling the pumped surfaces and $S_{\text {pumped }}$ is the pumped surface.

The ratio $C_{L E D}$, defined as the concentration factor [9] and written as the ratio of the output to the LED intensities (in $\mathrm{W} / \mathrm{cm}^{2}$ ) is also the ratio of the output radiance to the LED radiance assuming that both sources have Lambertian emission. In the case of a rectangular concentrator pumped on its two largest facets, $C_{L E D}$ can be written as :

$$
C_{L E D}=\eta_{o / o} \eta_{\text {fill }} 2 L / h
$$

with $L$ and $h$ the length and the thickness of the concentrator. 


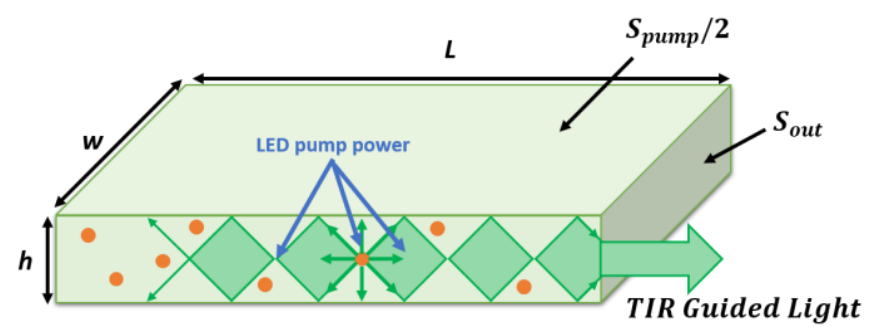

FIG.1. Schematic representation of a Ce:YAG Luminescent concentrator. $450 \mathrm{~nm}$ pump light is absorbed by Ce $\mathrm{e}^{3+}$ ions, $550 \mathrm{~nm}$ reemitted light is guided by TIR toward the edge of the concentrator.

In order to increase the output power of the concentrator, the first obvious step is to increase the pumped surface. Increasing the concentrator length L could be one option. However, it implies an increase of the optical path of light inside the concentrator and may affect the optical efficiency through the propagation losses. In our case we chose to increase the width of the slab, as this dimension does not affect the concentration factor. Hence, starting from a $\mathrm{L}=100 \mathrm{~mm} \mathrm{~h}=1 \mathrm{~mm} \mathrm{w}=9 \mathrm{~mm}$ Ce:YAG concentrator [9] we designed a new slab with the same L and h dimensions but a width $\mathrm{w}=14 \mathrm{~mm}$.

Equation (1) and (2) show that the output power and the concentration factor are both dependent to the filling factor. It is a key parameter. Indeed, in our previous setup [9], the filling factor was only of $19 \%$, because of the LED package. The recent chip scale package (CSP) can improve considerably this parameter. In this new LED concentrator, we used LED having $1.7 \mathrm{~mm}$ long, $1.3 \mathrm{~mm}$ wide package and only separated by $50 \mu \mathrm{m}$ from each other and arranged in eight lines of LEDs (Figure. 2). On a $14 \mathrm{~mm}$ wide concentrator, this enables a filling factor of $41 \%, 2$ times larger than the previous one. With the $2.5 \mathrm{~mm}$ wide concentrator, using only two lines of LED with head to tail contacts, the filling factor can even reach $58 \%$, at a cost of pump power, of course.

a)

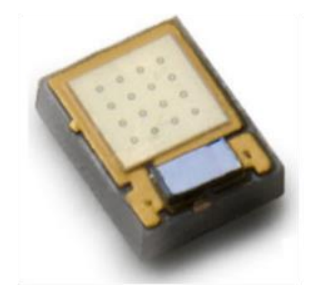

b)

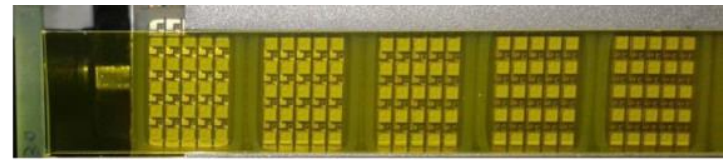

c)

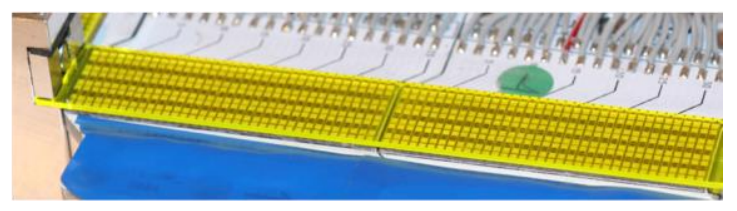

d)

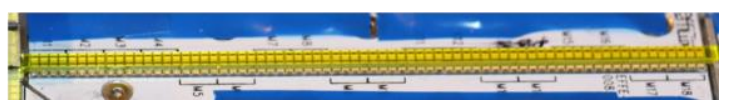

FIG.2. a) Picture of CSP LED, b) previous concentrator [9] and new ones : c) width of $14 \mathrm{~mm}$ and d) with of $2.5 \mathrm{~mm}$.

Our LC consist of a slabs of Ce-doped YAG, chosen in virtue of its high photoluminescence quantum yield (greater than $95 \%$ according to $[8,11]$ ) and for the good overlap between its absorption band and the emission spectrum of the blue LEDs (see Figure 3). The chosen length of our slabs is $100 \mathrm{~mm}$ and the thickness $1 \mathrm{~mm}$ (corresponding to a geometrical concentration factor $G=200)$. The thickness of the LCs $(1 \mathrm{~mm})$ was chosen to optimize the LED absorption for the doping concentration of the Ce ions of our sample $(0.25 \% \pm 0.05 \%))$. For LEDs with the spectrum shown in Figure 3, the pump absorption is about $95 \%$. The propagation losses of our LCs have been measured to be lower than $1.62 \times 10^{-2} \mathrm{~cm}^{-1}$. In this work, two concentrators with different widths $(2.5 \mathrm{~mm}$ and $14 \mathrm{~mm}$ respectively) have been tested. 


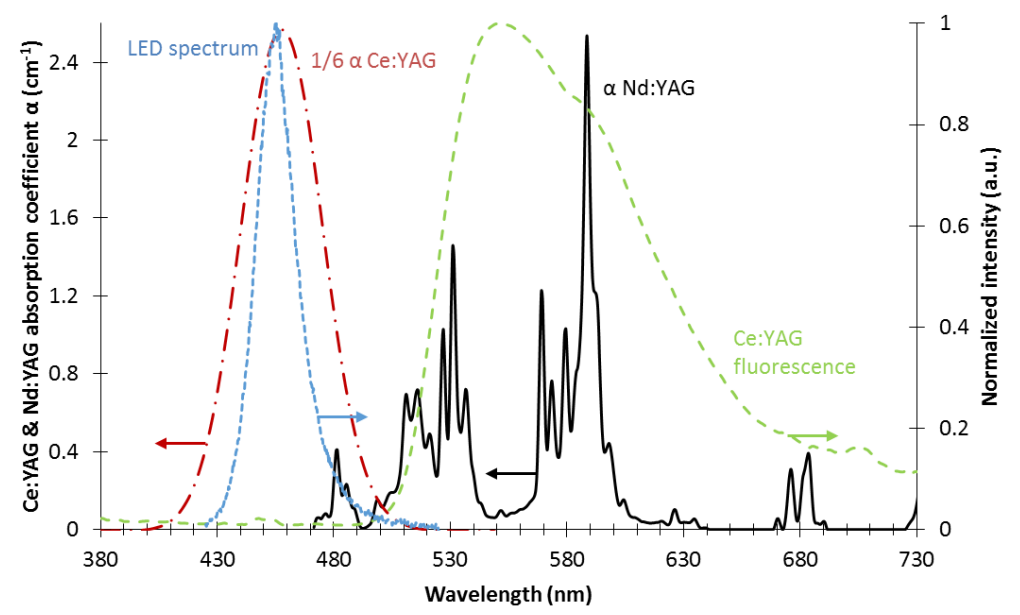

FIG. 3. Ce:YAG (red), Nd:YAG (black) absorption coefficient, emission spectra of Ce:YAG (green) and LED (blue) in the pulsed regime ( $250 \mu \mathrm{s}, 5 \mathrm{~A}, 10 \mathrm{~Hz}$, room temperature).

As pump source, we used blue LEDs with an emission spectrum centered on $450 \mathrm{~nm}$ (LUXEON Z Royal Blue from Lumileds), illustrated in Figure 3. Each LED emits an irradiance of $90 \mathrm{~W} / \mathrm{cm}^{2}$ at a continuous drive current of 1 A. Pulsing the injected current with a square shape, with a nominal current of $5 \mathrm{~A}$, during $250 \mu \mathrm{s}$, LED's irradiance increases to $315 \mathrm{~W} / \mathrm{cm}^{2}$. LED being a Lambertian emitter it corresponds to a radiance of $100 \mathrm{~W} / \mathrm{cm}^{2} / \mathrm{sr}$.

Table 1 summarizes the concentrator properties. A total of 1120 LEDs are used to pump the $14 \mathrm{~mm}$ luminescent concentrator compared to 350 LED in our previous work or 65 LED in the work by de Boer et al [8]. We measured the output power using a power meter at the output edge of the two concentrators (with an air gap between the LC and the power meter). The different results for the two concentrators in comparison to reference [9] are summarized in Table I.

\begin{tabular}{|c|c|c|c|c|}
\hline & \multicolumn{2}{|c|}{ Previous works } & \multicolumn{2}{c|}{ This work } \\
Properties & De Boer et al [8] & Barbet et al [9] & & \\
Width & $1.9 \mathrm{~mm}$ & $9 \mathrm{~mm}$ & $2.5 \mathrm{~mm}$ & $14 \mathrm{~mm}$ \\
Length & $52 \mathrm{~mm}$ & $100 \mathrm{~mm}$ & $100 \mathrm{~mm}$ & $100 \mathrm{~mm}$ \\
Thickness & $1.2 \mathrm{~mm}$ & $1 \mathrm{~mm}$ & $1 \mathrm{~mm}$ & $1 \mathrm{~mm}$ \\
Number of LED & 56 & 350 & 320 & 1120 \\
Filling factor (\%) & 56 & 19 & 58 & 41 \\
& & & & \\
Performance & 17 & 43 & 64 & 294 \\
Output peak power (W) & 5.1 & 2.6 & 7.0 & 6.0 \\
Concentration factor & 110 & 152 & 812 & 668 \\
Radiance (W/cm²/sr) & 21 & 6.6 & 6.1 & 7.2 \\
Optical efficiency (\%) & & & & \\
\hline
\end{tabular}

TABLE I. Properties and performance Ce:YAG luminescent concentrators studied in this work in comparison to previous works $[8,9]$. 
With the $2.5 \mathrm{~mm}$ and $14 \mathrm{~mm}$ concentrators, we obtained an output irradiance of $2.5 \mathrm{~kW} / \mathrm{cm}^{2}$ and $2.1 \mathrm{~kW} / \mathrm{cm}^{2}$ for an optical efficiency of $6.1 \%$ and $7.2 \%$ respectively. It corresponds to output peak powers of $64 \mathrm{~W}$ and $294 \mathrm{~W}$, this last measurement is 6.8 times higher than the previous demonstration (Barbet et al [9]).

This effort in densification allows then an output irradiance more than four times higher than the one recorded in ref [9]. For the $2.5 \mathrm{~mm}$ and $14 \mathrm{~mm}$ concentrators, the concentration factor $C_{L E D}$ are 7 and 6 meaning that the concentrators have a radiance 7 and 6 times higher than one LED alone. It corresponds to radiances of $812 \mathrm{~W} / \mathrm{cm}^{2} / \mathrm{sr}$ and $668 \mathrm{~W} / \mathrm{cm}^{2} / \mathrm{sr}$. Those concentrators enable a higher power scaling increasing at the same time the concentration factor.

This source can be used as ultra-bright simple innovative light source as it has been demonstrated very clearly in the paper of Boer et al [8]. Compared to Boer et al [8], we obtained a lower optical efficiency. This is related to the compound parabolic concentrator (CPC) bonded to the Ce:YAG crystal used in the ref [8]. In this configuration, the total internal reflections at the output surfaces are frustrated, increasing the light extracted from the concentrators. The same effect has been observed with our Ce:YAG concentrator bonded to a Nd:YAG crystal. With an optical adhesive having a refractive index of about 1.5, we estimated from our numerical simulations that the improvement factor due to the bonding is 2.5 , leading to optical efficiency higher than $15 \%$.

\section{LED CONCENTRATORS PUMPING Nd:YAG LASER FOR BRIGHTNESS IMPROVEMENT}

Luminescent concentrators exhibit a higher radiance than LED alone. It is possible to reach even higher radiance using the LED concentrator as a pump source for a laser. This brightness enhancement lies in the laser cavity filtering and energy storage in the upper laser level of the laser medium. As Ce:YAG emission is broad and do not significantly change with temperature, this pumping system is conceptually more robust than laser diodes and extremely less sensitive to the external environment. The $\mathrm{Ce}^{3+}$ emission band is in the yellow-red and covers the absorption bands of Nd:YAG (see Figure 3). This laser crystal appears to be an interesting choice because of its high quality and low cost. Moreover, its spectroscopic properties allow to operate easily in passively Q-Switched regime using an additional simple low-cost Cr:YAG crystal as saturable absorber (see part IV).

The laser crystal is pumped both longitudinally and transversely by the two concentrators described in the previous section (Figure.4). The Nd:YAG laser crystal has the following dimensions: 1 x $2.5 \times 14 \mathrm{~mm}^{3}$, matching with the dimensions of the LCs. The $\mathrm{Nd}^{3+}$ concentration in the laser crystal has been chosen to be 1 at. $\%$, that is to say as high as possible while avoiding concentration quenching [12]. All its faces are optically polished. One of the crystal laser facets $\left(1 \times 2.5 \mathrm{~mm}^{2}\right)$ is AR-coated with a reflectivity below $0.1 \%$ at $1064 \mathrm{~nm}$, while the other facet has a dichroic coating (HR at $1064 \mathrm{~nm}$ and HT over $550-650 \mathrm{~nm})$. 


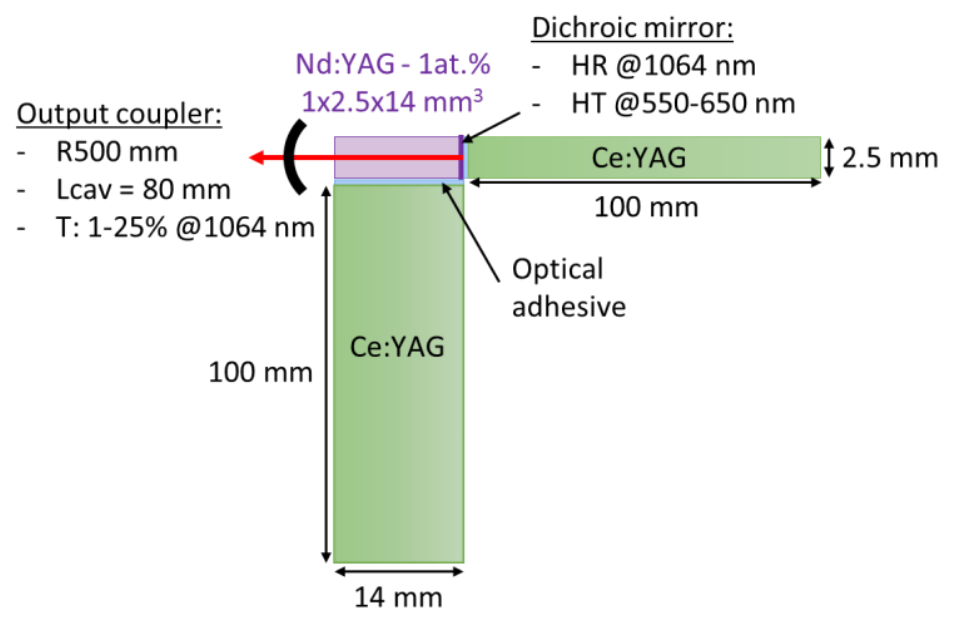

FIG. 4. Setup of the experiment. LEDs are placed above and underneath the Ce:YAG concentrators.

We first demonstrate laser operation in free running. To prevent any thermal effect in the crystal, LEDs operate at a frequency of $10 \mathrm{~Hz}$. We designed a plano-concave $80 \mathrm{~mm}$ long cavity with an output coupler having a radius of curvature of $500 \mathrm{~mm}$. We measured the laser output energy versus the input energy from the concentrators for a transmission output coupler of $25 \%$ (see Figure 5). By pulsing the LEDs with a current of 5 A during $250 \mu$ s (in accordance to the Nd:YAG lifetime) at a frequency of $10 \mathrm{~Hz}$, corresponding to an input pump energy from the concentrators of $204 \mathrm{~mJ}$, we obtained an output energy up to $5 \mathrm{~mJ}$, with an optical efficiency of $2.5 \%$, with a multimode profile. At this current, the total energy emitted from the 1440 LEDs is $1.27 \mathrm{~J}$, which corresponds to a global optical efficiency of $0.4 \%$. The maximum laser peak power is then $24.4 \mathrm{~W}$. In term of radiance, assuming a $\mathrm{TEM}_{11,1}$ the value is then $31.2 \mathrm{MW} / \mathrm{cm}^{2} / \mathrm{sr}$.

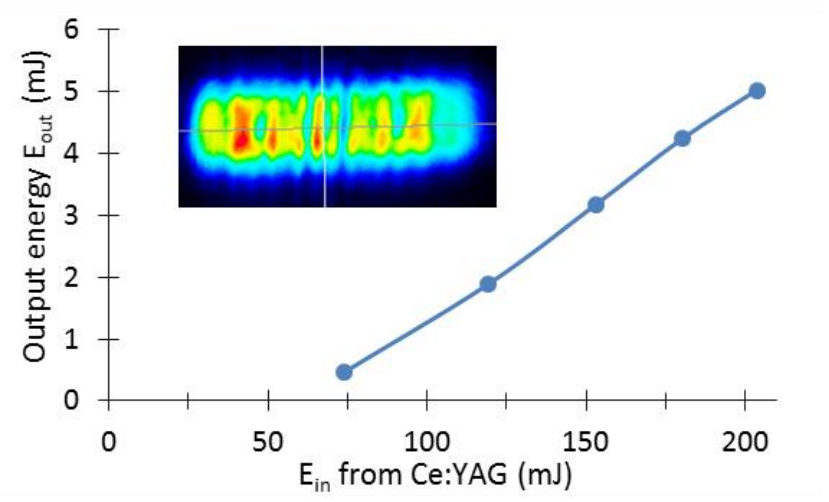

FIG. 5. Laser output energy in free running operation versus LC energy. LED are pulsed at 5 A during $250 \mu$ s at a frequency of $10 \mathrm{~Hz}$. The cavity is $80 \mathrm{~mm}$ long with an output coupler having a radius of curvature of $500 \mathrm{~mm}$ and a transmission of $25 \%$. Inset: Spatial profile at $5 \mathrm{~A}$. The mode size is $2 \mathrm{~mm}$ by $0.75 \mathrm{~mm}$, laser crystal facet being $2.5 \mathrm{~mm}$ by $1 \mathrm{~mm}$.

One has to mention that it is the first longitudinal pumping ever reported with a LED concentrator. This has been made possible by the width of the concentrator and its high filling factor. 


\section{PEAK POWER IMPROVEMENT BY Q-SWITCHED OPERATION}

The laser being characterized in free running operation, we investigated the passive Q-switched regime with Cr:YAG saturable absorber. This method is certainly the most simple and the less expensive to produced high peak power pulses.

We inserted $1.5 \mathrm{~mm}$ thick plates of Cr:YAG in the cavity. We tested two different Cr:YAG saturable absorbers with single pass initial transmissions $\mathrm{T}_{0}$ of $80 \%$ and $85 \%$. Due to transverse pumping configuration, single mode operation is not necessarily achieved. Indeed, several spatial modes and temporal regimes have been observed while adjusting the laser cavity. In order to validate single mode operation and its impact on the performance, let's explore these different operation regimes. First, when the pump duration is long compared to the pulse buildup time, the profile is highly multimode and multi temporal spikes can be observed with a fast photodiode. The total energy can be high but it is split in several pulses usually separated by a few tens of microseconds. To avoid this regime, one can either reduce the pump duration or increase the output coupler transmission. When the pumping duration is set to match the buildup time of the pulse, one can still observe multi-pulsing operation (see Figure 6). This regime can be related to spatial multimode operation, each mode having a different buildup time. Single mode operation can be obtained by careful adjustment of the cavity.

a)

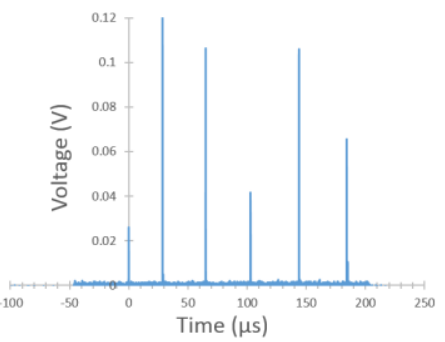

b)

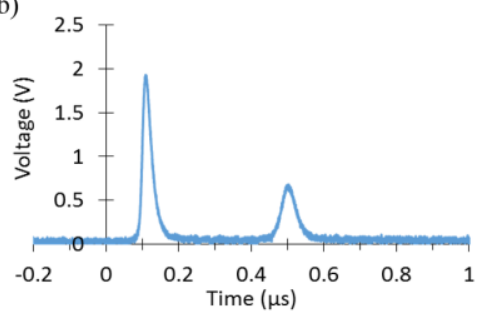

c)

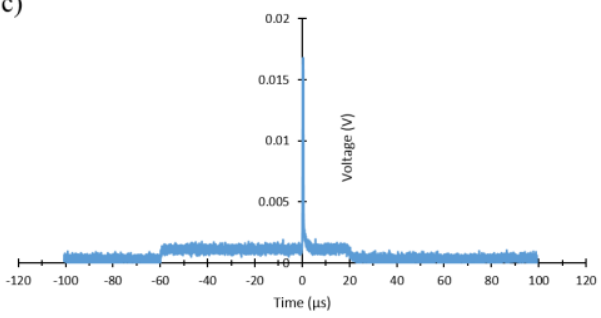

d)

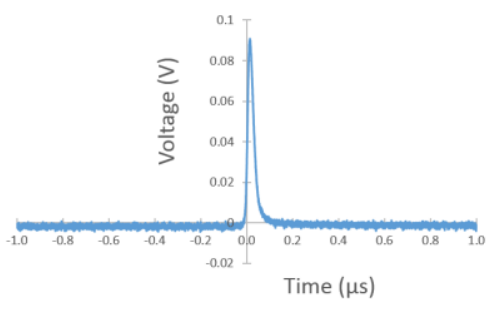

FIG. 6. Temporal representation of the modes we discussed. a) Multimode, b) quasi-monomode c) and d) TEMoo mode on different time scales for a $80 \mu$ s pump duration.

Following the beam profile observed in free running operation, we investigated single mode operation on a highly order mode. Indeed, one can take advantage of the pumping geometry in which $\mathrm{TEM}_{\mathrm{N}, 0}$ modes exhibit better overlap with the pump

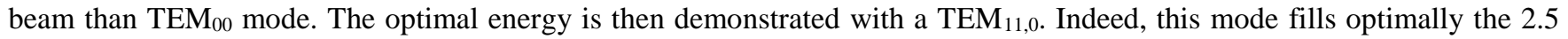
$\mathrm{mm}$ wide crystal used in the experiment as shown in Figure 7. In this high order mode configuration, energy up to $2.26 \mathrm{~mJ}$ has been demonstrated with similar parameters (saturable absorber transmission $\mathrm{T}_{0}=85 \%$, output coupler $\mathrm{T}=25 \%$ ). We adjusted the pump duration at $300 \mu \mathrm{s}$ in order to have a single pulse operation.. The pulse duration is around 40 ns. The average power reached $22.6 \mathrm{~mW}$ with a peak power of $60 \mathrm{~kW}$. In this case, the maximum radiance reaches $230 \mathrm{GW} / \mathrm{cm}^{2} / \mathrm{sr}$ with a diffraction-limited $\mathrm{TEM}_{11,0}$ beam. 


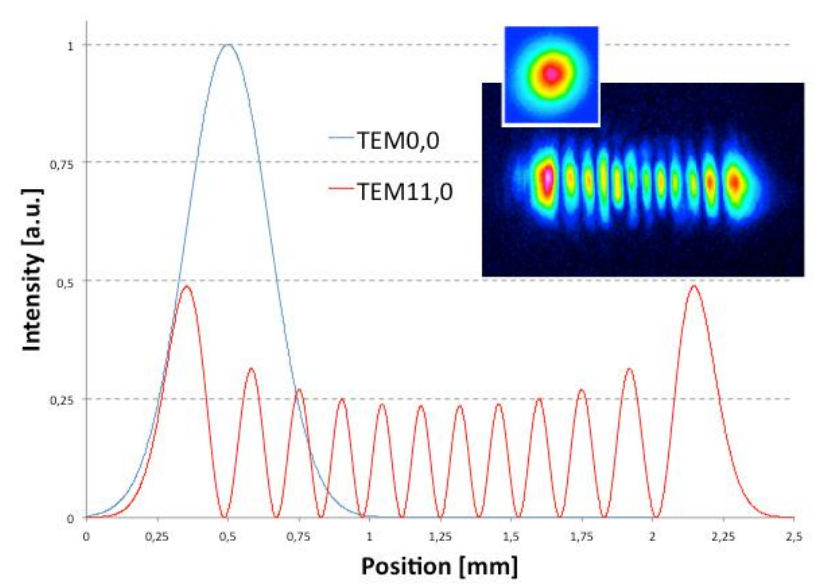

FIG. 7. High order mode Q-switched operation: enhancement of the beam size at normalized energy.

In the following, we discuss the results obtained with the two saturable absorbers and with different output couplers, when the cavity was aligned for $\mathrm{TEM}_{00}$ operation. The results are summarized on Figure 8. Output energies varied from $50 \mu \mathrm{J}$ to $270 \mu \mathrm{J}$ and best performance was obtained with the saturable absorber having the lowest transmission $\mathrm{T}_{0}=80 \%$. The pulse duration varies from $33 \mathrm{~ns}$ to $45 \mathrm{~ns}$, the $\mathrm{T}_{0}=80 \%$ saturable absorber giving the shortest pulses.

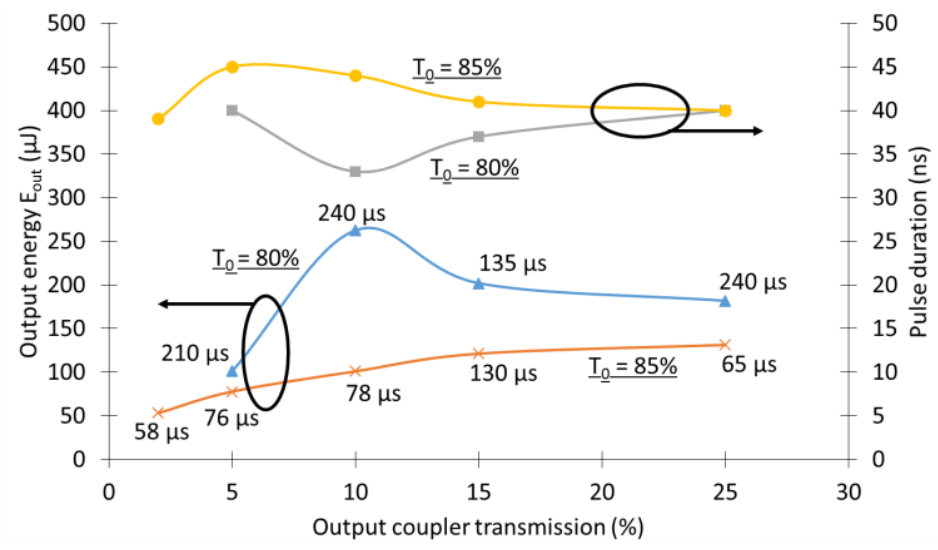

FIG. 8. Single-mode output energy and pulse duration in Q-switched operation as a function of the output coupler transmission, for each saturable absorber $\left(\mathrm{T}_{0}=80 \%\right.$ and $\left.\mathrm{T}_{0}=85 \%\right)$. Build-up time is indicated on the energy curves. The cavity length is $80 \mathrm{~mm}$.

The buildup times are also reported on Figure 8 for each configuration. It shows an erratic variation resulting from the difficulty to operate in $\mathrm{TEM}_{00}$ : alignment of the cavity has to be combined with the adjustment of the pump duration to avoid multipulsing. The highest output peak power is $8 \mathrm{~kW}$, with an energy of $263 \mu \mathrm{J}$ achieved in a $33 \mathrm{~ns}$ pulse duration (Figure 9). These performances have been obtained with the $10 \%$ transmission output coupler. Beyond this transmission, the output energy starts to decrease (and so the peak power, even if the pulse lengths are still shorter than with the $\mathrm{T}_{0}=85 \%$ saturable absorber). 


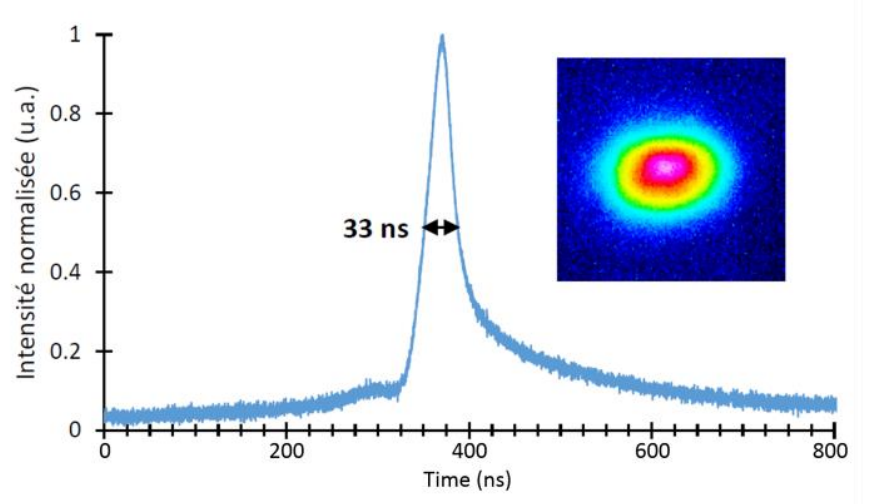

FIG. 9. Temporal and spatial profiles of the output laser, with an energy of $263 \mu \mathrm{J}$. Pump pulse duration of $250 \mu \mathrm{s}$ with the $80 \%$ initial transmission saturable absorber and the $10 \%$ transmission output coupler, $\mathrm{R}=500 \mathrm{~mm}$. Cavity length $=80 \mathrm{~mm}$.

As expected, the energy per pulse is lower than in $\mathrm{TEM}_{11,0}$ operation. However it corresponds to a higher radiance : 706 $\mathrm{GW} / \mathrm{cm}^{2} / \mathrm{sr}$. It corresponds to an improvement factor of 22000 in terms of radiance compared to the free running laser operation. The main radiance enhancement stages are sum up in Table II.

\begin{tabular}{|c|cccc|}
\hline \multirow{2}{*}{ Light Emitter } & LED & LC & Nd:YAG free running & Nd:YAG Q-switched \\
\cline { 2 - 5 } Wavelength (nm) & 450 & 550 & 1064 & 1064 \\
Radiance & $100 \mathrm{~W} / \mathrm{cm}^{2} / \mathrm{sr}$ & $812 \mathrm{~W} / \mathrm{cm}^{2} / \mathrm{sr}$ & $31.2 \mathrm{MW} / \mathrm{cm}^{2} / \mathrm{sr}$ & $706 \mathrm{GW} / \mathrm{cm}^{2} / \mathrm{sr}$ \\
\hline
\end{tabular}

TABLE II. Summary of the different radiance enhancement stages presented in this paper.

\section{CONCLUSION}

We used LEDs having an radiance of $100 \mathrm{~W} / \mathrm{cm}^{2} / \mathrm{sr}$ at $450 \mathrm{~nm}$ to pump Ce:YAG luminescent concentrators. By careful design of the concentrator, we improved significantly the filling factor and the output power. Ce:YAG concentrator can be seen as a new light source having a radiance of $668 \mathrm{~W} / \mathrm{cm}^{2} / \mathrm{sr}$ at $550 \mathrm{~nm}$ with a peak power of $294 \mathrm{~W}$ : an order of magnitude higher than the previous work.

Passively Q-Switching this laser with Cr:YAG plates, this LED pumped source produce pulses with a duration of $33 \mathrm{~ns}$ and an energy of $263 \mu \mathrm{J}$. It corresponds to a peak power of $8 \mathrm{~kW}$ and an average power of $2.6 \mathrm{~mW}$ at $10 \mathrm{~Hz}$. This leads to a maximum radiance of $706 \mathrm{GW} / \mathrm{cm}^{2} / \mathrm{sr}$ for a diffraction-limited beam. It is worth to note that the results are far above the first performance reported in 1984 [10].

In addition, we demonstrated the first longitudinal pumping of a Nd:YAG by a LED concentrator. This pumping is adapted to very short cavities able to emit shorter pulses and to increase the radiance a step further. It opens the way to LED pumped passively Q-switched mini lasers or even microchip lasers.

Finally, this unique combination of LED, Ce:YAG luminescent concentrators and passively Q-switched Nd:YAG laser results in a very robust source combining the LED advantages like long lifetime and low-cost with the advantages of laser sources like high radiance and high peak power. 


\section{ACKNOWLEDGEMENTS}

We greatly thank Sophie Coumar and Christian Beurthe from the optical workshop of the Laboratoire Charles Fabry for their precious help for bonding the crystals. We also thank our funding agencies: Agence Nationale de la Recherche (ANR-12BS09-0012-01), Labex (ANR-10-LABX-0039) and Conseil Général de l’Essonne.

\section{REFERENCES}

1. «Haitz's law», Nature Photonics, 1, 23 , (2007) (DOI 10.1038/nphoton.2006.78, Bibcode 2007NaPho...1...23.).

2. T.Y. Fan and R.L. Byer "Diode-pumped solid state lasers" IEEE J of Quantum Elect. 24 895-911 (1988).

3. A. Barbet, F. Balembois, A. Paul, J.-P. Blanchot, A.-L. Viotti, J. Sabater, F. Druon, and P. Georges, "Revisiting of LED pumped bulk laser: first demonstration of Nd:YVO4 LED pumped laser,” Opt. Lett. 39, 6731 (2014).

4. B. Villars, E. S. Hill, and C. G. Durfee, "Design and development of a high-power LED-pumped Ce:Nd:YAG laser," Opt. Lett. 40, 3049 (2015).

5. K.-Y. Huang, C.-K. Su, M.-W. Lin, Y.-C. Chiu, and Y.-C. Huang, "Efficient 750-nm LED-pumped Nd:YAG laser," Opt. Express 24, 12043 (2016).

6. M. Debije, P Verbunt, “Thirty Years of Luminescent Solar Concentrator Research: Solar Energy for the Built Environment," Advanced Energy Materials, 2, 12-35 (2012).

7. P. Dorenbos, C. Eijk, "Inorganic scintillators and their applications," Delft University, (1995).

8. D. de Boer, D. Bruls, H. Jagt, "LED-based projection source based on luminescent concentration," Opt. Express 24, A1069 (2016).

9. A. Barbet, A. Paul, T. Gallinelli, F. Balembois, J.-P. Blanchot, S. Forget, S. Chénais, F. Druon, and P. Georges, "Light-emitting diode pumped luminescent concentrators: a new opportunity for low-cost solid-state lasers," Optica 3, 465 (2016).

10. L. I. Kuratev, Izv. Akad. Nauk "Solid-state lasers with semiconductor pumping," SSSR. Seriya Fiz. 48, 1564 (1984).

11. P. Gorrotxategi, M. Consonni, and A. Gasse, "Optical efficiency characterization of LED phosphors using a double integrating sphere system,” J. Solid State Light. 2, 1 (2015).

12. Z. Huang, Y. Huang, Y. Chen, and Z. Luo, "Theoretical study on the laser performances of Nd3+:YAG and Nd3+:YVO4 under indirect and direct pumping,” J. Opt. Soc. Am. B, 22, 2564 (2005). 